\title{
Experimental Investigations of Induction Heating in Warm Forming of Stainless Steel Sheets
}

\author{
Robert SMUSZ, Tomasz TRZEPIECINSKI, Tomasz MALINOWSKI, Tomasz PIEJA
}

\begin{abstract}
The main objective of this study is to investigate the effect of heating conditions on the temperature distribution in sheet metal. An AMS5604 stainless steel sheet was heated in an induction heater. Then, the hot workpiece was transported to the stamping tool. The uniform temperature distribution is a key factor influencing the possibility of forming and quality of warm-formed parts. To study the temperature distribution in sheet plate we carried out the measurements using termoelements. Furthermore, thermovisual measurements were performed using a FLIR P 640 thermovisual camera. It was found that to improve the uniformity of the temperature distribution in the workpiece the time of heating should be increased. However, the time of transport of the sheet to the tool should be decreased. During air cooling a decrease of the difference between the maximal and minimal temperature of the sheet is observed.
\end{abstract}

Keywords: AMS5604 alloy; emissivity; forming tool; sheet metal forming; temperature

\section{INTRODUCTION}

Stainless steel is an iron-based alloy that contains various combinations of other elements to provide suitable characteristics for technological applications and to make stainless steel stainless. By definition, any steel that contains a minimum of $11 \%$ chromium is a stainless steel. This minimum chromium content in the steel produces a rich, transparent oxide film, which protects it from corrosion and oxidation.

As stainless steel used in aerospace applications has a surface finish that must be preserved, the methods used in fabrication technology of aircraft components are more exacting than those used for low-carbon elements $[1,2]$. In general, stainless steels have the following characteristics, as compared with the carbon steels:

- greater strength and susceptibility to work hardening,

- higher propensity to gall to tooling,

- lower heat conductivity.

The relationship between the work hardening and the strain rate hardening is fundamental to understanding sheet metal forming at elevated temperatures and was studied by Larsson [3]. The decrease of the strain-hardening exponent with increasing temperature is compensated by the strain rate hardening effect, which becomes more pronounced with increasing temperature [4]. Stachowicz et al. [5] presents results from an investigation of the effect of temperatures in the range of 20 to $700{ }^{\circ} \mathrm{C}$ on basic material parameters of AMS5604 stainless steel sheet, such as yield stress, ultimate strength, total and uniform elongation, strain hardening parameters and plastic anisotropy factor. In austenitic stainless steel, martensite formation takes place, which is not only affected by temperature but also influenced by the rate at which the material is deformed. The temperature range concerning steel during warm metal forming processes is approximately 600 to $800{ }^{\circ} \mathrm{C}$ [6]. In comparison with the conventional sheet metal forming processes, warm forming requires an initial increasing of the blank temperature before the forming stage. Two distinct strategies can be adopted for the heating process [7]:

- generate a uniform temperature in the whole blank,
- apply a gradient of temperatures in selected regions of the blank.

Concerning the method of heating the whole blank, the heating of the blank can be carried out using two different heating methods [7]:

- external heating in furnaces, induction systems or direct/indirect resistance systems,

- $\quad$ internal heating by conduction through heated tools.

The temperature distribution in the blank immediately before the forming operation is a key point for the success of warm sheet metal forming operations [18]. Other methods of blank heat during the forming process are irradiation of the sheet with a laser beam using Laser Assisted Deep Drawing (LADD) developed by Schuöcker and Schröder [9].

The objective of the work done by Harrison et al. [10] was to develop a warm forming process that both retains the benefits of traditional warm forming while allowing for the use of lower-cost tooling. The results revealed that nonisothermal warm forming could enable sufficient formability to stamp a one-piece door inner panel from commodity aluminium alloys. Takuda et al. [11] reported that in order to find the optimal conditions of warm forming of aluminium alloy sheets and to put it into practical use, it is indispensable to analyse not only the mechanical properties that depend on the temperature but also the heat conduction during forming. They used a heating tool and heated the blank via imbedded electric resistance heaters before placing it into the die. The forming tools (die and blank-holder) were heated together with the blank sheet until $250^{\circ} \mathrm{C}$ and then assembled in the press. Lade et al. [12] studied the microstructure changes and formability of the austenitic stainless steel 304 after warm deep drawing. They also heated the blank and the die using a furnace mounted over the universal testing machine in order to control the specimen temperature with the accuracy of $\pm 0.1^{\circ} \mathrm{C}$.

The uniform temperature distribution is a key factor influencing the possibility of forming and quality of warmformed parts. This article presents the results of analysis of the effect of heating conditions on temperature distribution 
in an AMS5604 stainless steel sheet heated in an induction furnace. The temperature was measured using thermoelements and a thermovisual camera. In the next section, the methodology and experimental measurements are explained, followed by presentation of results and discussion.

\section{METHODS OF WORKPIECE HEATING 2.1 Resistance Heating}

In the resistance heating method, the work sheet is considered as a resistor and high current is applied to the sheet [12]. The material resistance to the passage of current produces heat by Joule's effect [7]. The rate of material heating is directly related to the electrical resistance of the material [13]. The variation of sheet thickness of the blank in the current direction yields a non-uniform temperature in the blank volume [14]; thus, this method is limited to sheets with a constant cross-section. Yanagimoto and Izumi [15] developed a new hot forming system for highalloy metals with poor workability. This forming system is a direct combination of a forming machine and continuous electric resistance heating and is capable of high-speed forming of metals with flexible and precise control of elevated temperatures. Mori et al. [16] proposed a method of resistance heating for the hot and warm sheet stamping of high-strength steel sheets. They examined the effects of the heating temperature on the spring back and formability of ultra-high tensile strength steel sheets. Ghosh et al. [8] investigated the mechanical behaviour of Al-Mg-Si alloys at warm temperatures using a Gleeble thermomechanical simulator. Among the parameters investigated, temperature was found to have the most significant effect on the force-displacement response.

\subsection{Induction Heating}

In this technique the heat is a result of the Joule's effect [4]: heat is generated proportional to $I^{2} R$, where $I$ is the magnitude of current and $R$ is the resistance of material [17].The application of an alternating current in an induction coil generates a magnetic field, which induces eddy currents in electrically conductive objects located in the vicinity of the coil [7]. Induction heating exhibits a few advantages, including precise temperature heating in the desired heat zone and quick processing time with no exposed flames or heating elements. The rate of heating of the formed part depends on the frequency and the intensity of the induced current, as well as the material properties, such as specific heat, magnetic permeability and electrical resistivity [18]. The Transverse Flux Induction Heating (TFIH) method has taken the place of conventional methods like gas-fired or electrical resistance heating techniques and it can be used with great flexibility and efficiency in both ferrous and non-ferrous materials [17].

\subsection{Heating by Conduction with Heated Forming Tools}

The most common way of heating the blank through conduction is by placing the blank between hot tools. In this case, both the die and the blank-holder are pre-heated to the warm forming temperature [19], while the blank is heated by contact conduction with the tools when it is clamped between the blank-holder and die. The technique commonly used in industry is still the uniform heating of the blank [3]. In some cases the punch and/or die is cooled by water or by air and in some cases the blank holder is heated [3]. The main disadvantage of heating by conduction is that a large amount of tool material volume has to be heated and the time required to achieve a suitable uniform temperature of the workpiece might be high [7]. However, the workpiece is heated in the forming position, so the loss of heat during the transport stage is avoided [20].

\section{MATERIAL AND METHODS}

In order to prove the applicability of the induction heating process of stainless steel sheets for sheet metal stamping, investigations of temperature distribution in sheet metal plates were carried out. The induction heater used in investigations is a part of a special work centre (Fig. 1) for forming aircraft components. In this centre the sheet is transferred from the heater to the stamping die using an industrial robot. The moment of workpiece transfer is controlled by special software and the pyrometer reading the temperature in one point of the workpiece. In industrial conditions there is no possibility to measure the temperature distribution in the whole volume of each workpiece.

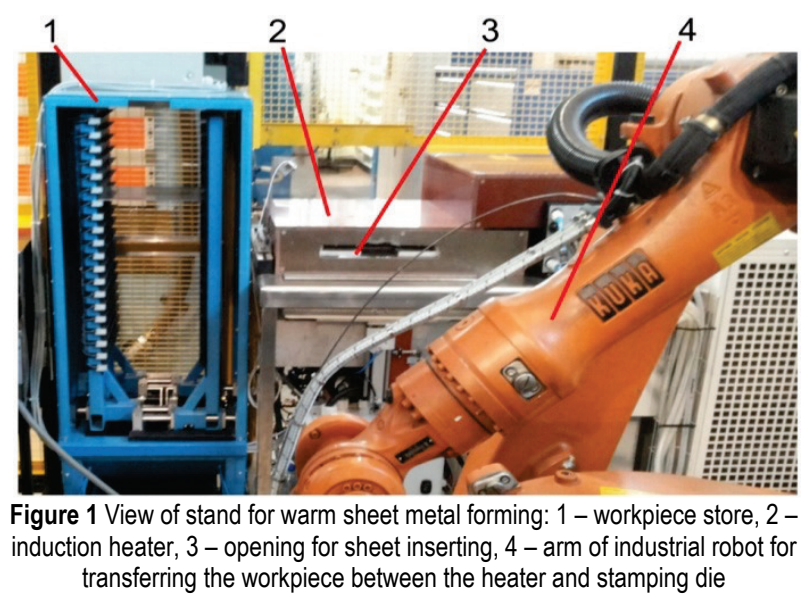

The thermal analysis of the temperature state in the sheets was carried out during heating an AMS5604 stainless steel sheet with a thickness of $1.6 \mathrm{~mm}$. The chemical composition of tested sheet is presented in Table 1. AMS5604 alloy is a martensitic stainless steel that provides an outstanding combination of good corrosion resistance and high strength, and is used extensively in the aerospace industry for various aircraft components [21].

Table 1 Chemical composition of tested sheets (wt. \%)

\begin{tabular}{|c|c|c|c|c|c|c|c|}
\hline $\mathrm{Cr}$ & $\mathrm{Ni}$ & $\mathrm{Cu}$ & $\mathrm{Mn}$ & $\mathrm{Mo}$ & $\mathrm{Si}$ & $\mathrm{Nb}$ & $\mathrm{C}$ \\
\hline 16,5 & 4,0 & 4,0 & 1,0 & 0,5 & 1,0 & 0,3 & 0,07 \\
\hline
\end{tabular}

In the first part of our investigation, experimental research was performed to verify and optimise the parameters of sheet heating using an induction heater (Fig. 2). The dimensions of the square blank were $292 \times 292$ $\mathrm{mm}$. In the coil of the heater, there are cordierite inserts that allow the accumulation of heat and accelerate heating of subsequent batches during the manufacturing cycle. 




Figure 2 Induction heater

The study included measurements of temperature distribution in the blank heated in the induction heater using thermography and thermocouples. Uniform temperature distribution is one of the key factors that affect the quality of warm-formed parts; therefore, the investigations are focused on the identification of the temperature distribution on the whole surface of the blank. Information regarding the non-uniformity of the temperature distribution will help to optimise the parameters of the heating operation. In order to optimise the heating process, the experimental measurements were carried out in industrial conditions.

Measurement of the temperature distribution in blanks was performed using five jacketed type-K thermocouples, with a diameter of $1 \mathrm{~mm}$, placed in spark-machined holes in the sheet. The locations of the thermocouples in the holes of the blank are shown in Fig. 3.



Figure 3 Location of thermocouples

Registration of measurement data takes place using the GL220 midi Logger (Graphtec) recorder with an accuracy of $0.1 \%$. The temperature of the so-called cold junctions of the thermocouples is compensated internally using a temperature sensor installed in a DVR Graphtec recorder. The ambient temperature is measured using an EMT-302 temperature gauge (CZAKI) with an accuracy of $0.3 \% \mathrm{~T} \pm$ $1{ }^{\circ} \mathrm{C}$. Distributions of temperature on the sheet surface were determined using an FLIR P 640 thermal imaging camera with sensitivity spanning the 8 to $14 \mu \mathrm{m}$ wavelength range. Thermographic measurements were performed in a stationary state in a conditioned room.
Before starting the fundamental temperature measurements, time synchronisation of the recorder and the camera was made using an infrared camera and thermocouples. It was necessary to interrelate the obtained results. Then thermocouples were installed in the holes and the sheet surface was cleaned with acetone to remove impurities. After starting the GL220 recorder, the sheet was placed in a heater where it was kept until it had reached the required temperature. The opening in the heater for the insertion and removal of the sheet was automatically closed after the start of the heating process with a special cover. Immediately after removing the sheet from the heater the image was made using the infrared camera. To make this image the sheet was placed on a cylindrical base with a thickness of about $2 \mathrm{~mm}$. Upon completion of recording of measured data the depth of penetration of the installed thermocouples in the joint holes was measured.

The measurement conditions were as follows:

- room temperature $20.5^{\circ} \mathrm{C}$,

- apparent temperature (temperature of surrounded surfaces) $22.4^{\circ} \mathrm{C}$,

- relative humidity $60 \%$.

Before performing the thermovisual measurements, the measurement of the temperature reflected from radiation sources surrounding the test object (in this case the sheet) was carried out. For this purpose, a diffusion mirror was used (Fig. 4), which was placed on the cylindrical base. The location of the mirror and the infrared camera during the measurement of reflected temperature was the same as in the basic thermovisual research, which provided constant measuring conditions. The average temperature reflected from the selected area of the diffusion mirror was measured using the infrared camera. The temperature was $22.4{ }^{\circ} \mathrm{C}$. The measurement of reflected temperature was carried out in accordance with the standard ISO 18434-1: 2008 [22]. Furthermore, the measurement of room temperature was carried out using an EMT-302 temperature instrument.

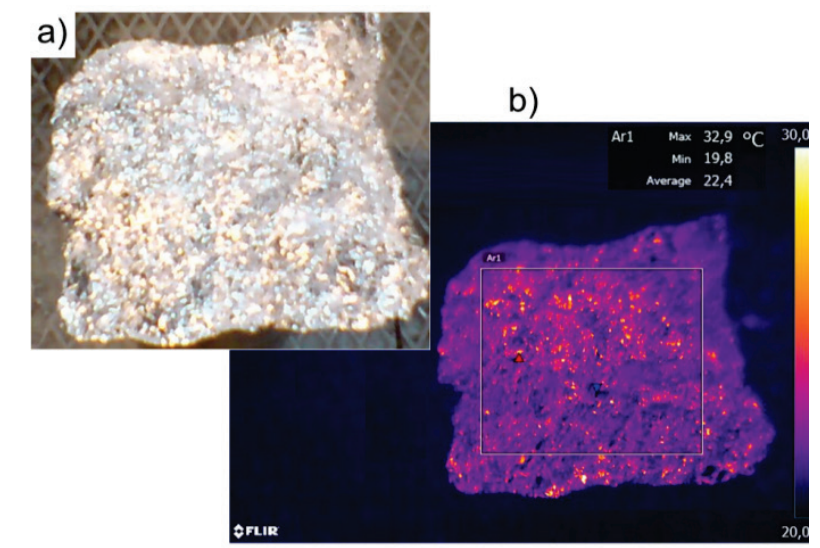

Figure 4 Diffusion mirror (a) and reflected temperature distribution (b)

In this case, the identification of reflected temperature is crucial for measuring the temperature using an infrared camera, due to very low emissivity of the tested sheet.

The measurements of emissivity in temperature range between $300{ }^{\circ} \mathrm{C}$ and $900{ }^{\circ} \mathrm{C}$ are carried out using Gleeble 3800 thermomechanical simulator (Fig. 5) and thermovisual camera. The Gleeble 3800 testing system 
heats the sheet by direct resistance, which changes applied current intensity to achieve a target temperature in the centre of the specimen.

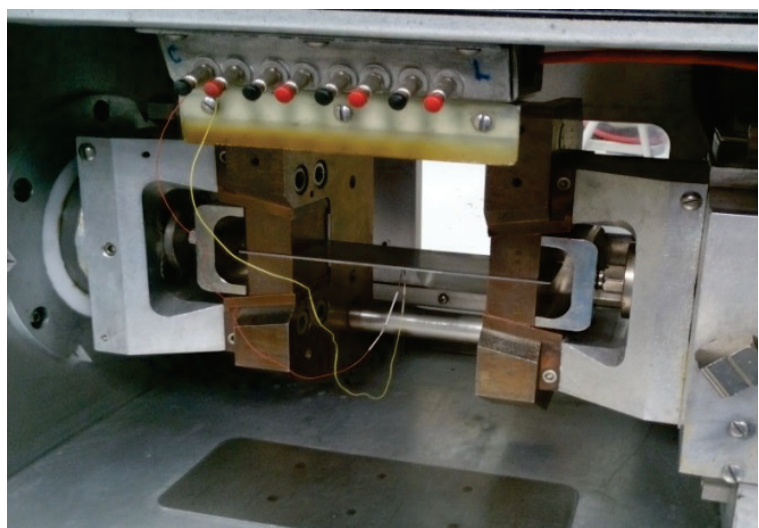

Figure 5 Clamping the sheet in the Gleeble simulator to determine the shee emissivity

\section{RESULTS AND DISCUSSION}

For accurate measurement of the sheet temperature using a pyrometer, the emissivity of the sheet surface has to be found. The sheet was heated to selected temperatures (between $300{ }^{\circ} \mathrm{C}$ and $900{ }^{\circ} \mathrm{C}$ ). The emissivity was determined based on the picture of the temperature distribution (see example in Fig. 6) prepared using a thermovisual camera after reaching the reference temperature. A list of sheet surface emissivity is shown in Tab. 2 .

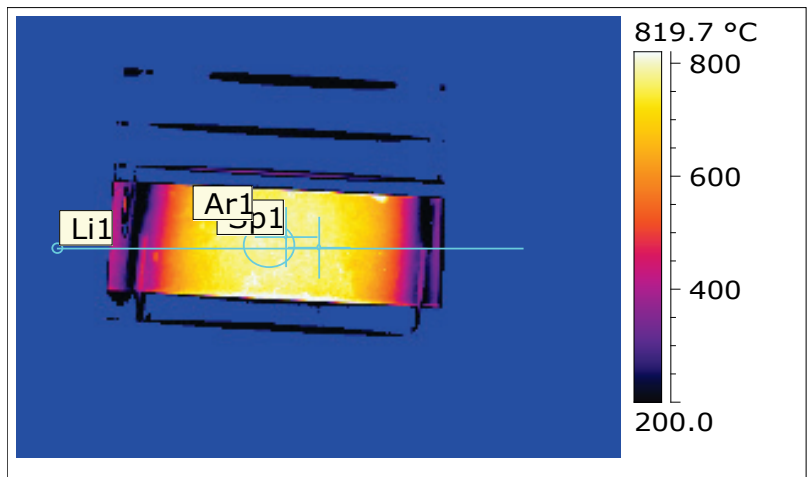

Figure 6 The example of temperature distribution in the sample (reference temperature $800^{\circ} \mathrm{C}$ )

Table 2 The values of emissivity for analysed temperatures

\begin{tabular}{|c|c|c|}
\hline $\begin{array}{c}\text { Reference } \\
\text { temperature, }{ }^{\circ} \mathrm{C}\end{array}$ & Emissivity & $\begin{array}{c}\text { Average temperature in } \\
\text { central area } \mathrm{Ar} 1,{ }^{\circ} \mathrm{C}\end{array}$ \\
\hline 300 & 0,06 & $* 302,4$ \\
\hline 400 & 0,10 & 395,0 \\
\hline 500 & 0,11 & 502,9 \\
\hline 600 & 0,12 & 607,0 \\
\hline 700 & 0,13 & 698,2 \\
\hline 800 & 0,14 & 784,1 \\
\hline 900 & 0,15 & 908,9 \\
\hline
\end{tabular}

The results of the temperature distribution determined using thermocouples are shown in Figs. 7-9. The highest temperature is reached in the upper left corner of the sheet (T4 in Figs. 7 and 8) and the lowest temperature is at the upper edge of the plate (T3 in Figs. 7 and 8). Temperature values measured using other thermocouples (T1-T2 in Figs. 7 and 8) are little different from each other.

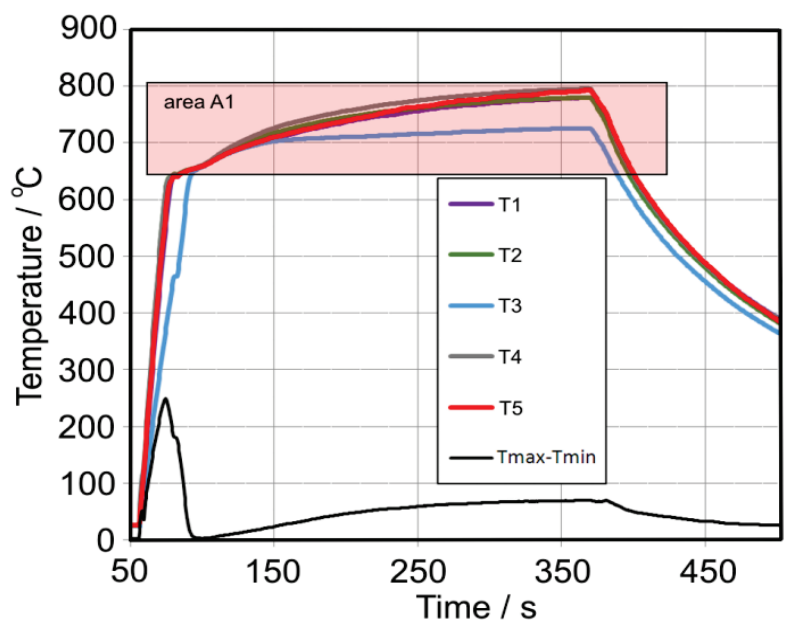

Figure 7 Variation of temperature measured using termocouples as a function of heating time

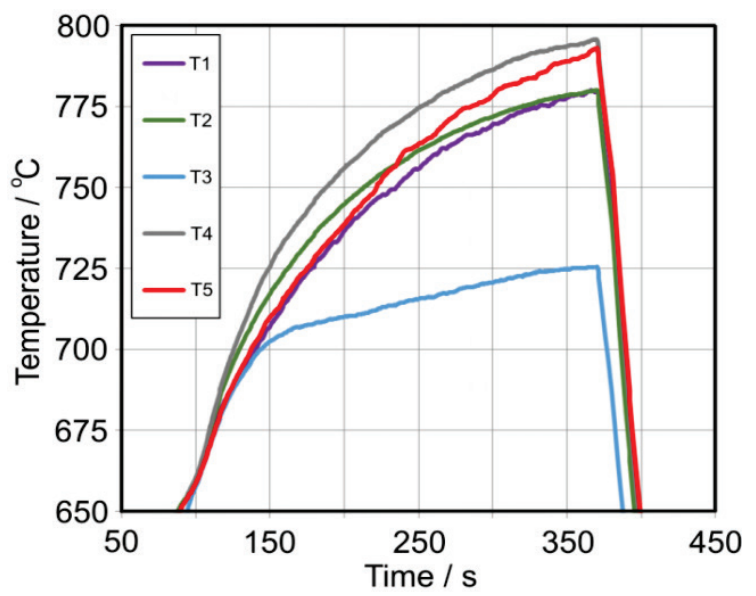

Figure 8 Variation of temperature vs. time for area A1 illustrated in Fig. 7

In an initial heating phase, a very rapid increase in temperature difference occurs between the maximum and minimum temperatures $T_{\max }-T_{\min }$ (Fig. 7), which is probably the result of inhomogeneities in current intensity in the sheet material. The maximum temperature difference reached is approximately $250{ }^{\circ} \mathrm{C}$ and in the final phase of the heating (just before switching on the heater) this falls to approximately $70{ }^{\circ} \mathrm{C}$. This contributes to heterogeneity of the heat flux generated in the sheet material. In the second phase, when the temperature exceeds $650{ }^{\circ} \mathrm{C}$, the difference between the maximum and minimum temperature decreases to almost $0{ }^{\circ} \mathrm{C}$ and then slowly increases until the heater is switched off. In this heating phase, a major factor contributing to the lower temperature in the vicinity of the upper edge of the sheet is heat lost to the environment by radiation and convection. The difference in the temperature measurement using thermocouples T1, T2, T4 and T5 does not exceed $20^{\circ} \mathrm{C}$ (Fig. 8). Some part of this temperature difference can be considered as measurement error. Furthermore, since the current density decreases exponentially towards the body centre, leading to a non-uniform current distribution within the body, the so-called skin effect is directly related to the induction heating system [7]. The inhomogeneity of the temperature gradient comes about as a result of Joule heat flowing from edge to centre [23]. Point T3 is located close to the heater opening and the temperature at this point is 
about $60{ }^{\circ} \mathrm{C}$ lower that the rest of thermocouples. This is a result of heat loss by conduction into metal flat nose pliers during the stage of transferring the blank to stamping die.

The major advantage of induction heating in comparison with the conventional heating method is the short heating time [23]. Fig. 9 shows that the complete induction heating process for the heated region needs only about 300 seconds to be heated up to $750{ }^{\circ} \mathrm{C}$.

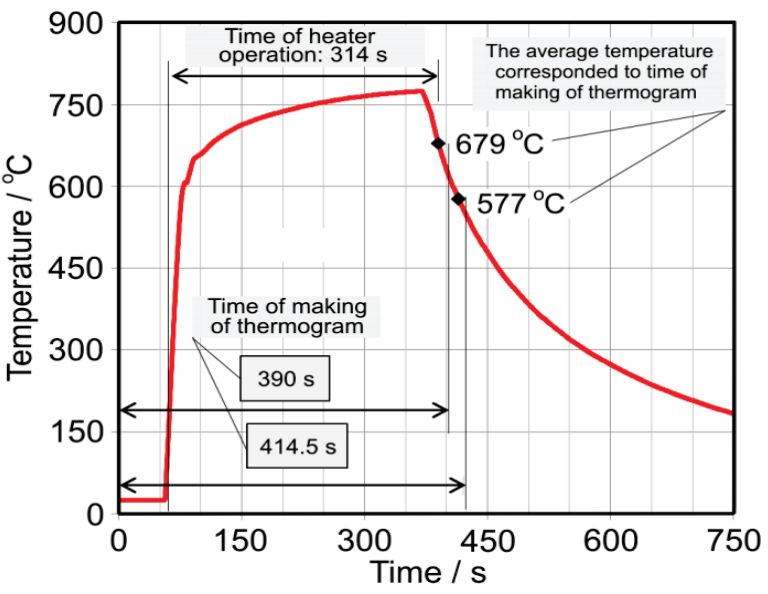

Figure 9 Average temperature vs. time

Fig. 10 shows the thermal photograph made after the recorder is launched (i.e., 390 seconds).

The sheet edge gripped by tongs

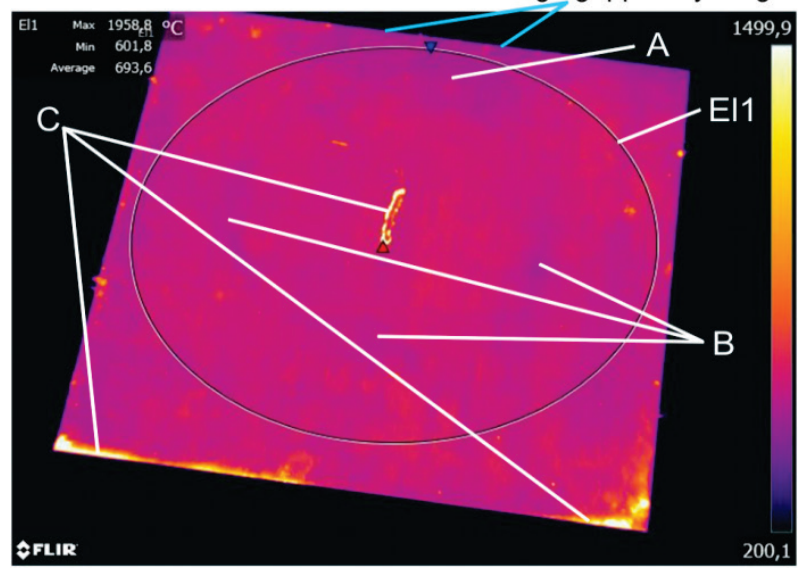

Figure 10 Thermogram I: identification of average temperature after time of 390 seconds

In order to compare the results of the thermogram and the arithmetic average temperature determined using thermocouples, the average temperature in the area EL1 (Fig. 10) is determined, which amounted to $694{ }^{\circ} \mathrm{C}$. The discrepancy between the values of these temperatures is $15^{\circ} \mathrm{C}$, which represents only $2 \%$ of the temperature determined using the thermocouples. For the thermogram depicted in Fig. 11 the average temperature of the area EL1 is $578^{\circ} \mathrm{C}$, while the average temperature obtained using the thermocouples was $577^{\circ} \mathrm{C}$. This illustrates a satisfactory convergence of the results obtained via the conventional method and thermography.

Radiative heat losses to the environment and losses by conduction when removing the sheet from the heater using metal flat nose pliers cause a decrease of the temperature in the vicinity of the sheet (detail A in Figs. 10-14).
Contact of the workpiece with the surface of the cylindrical base causes local temperature reduction (detail $\mathrm{B}$ in Figs. 10 and 11) by conduction of heat. Due to the fact that the sheet surface has a very low emissivity (0.14), which means a very high reflectivity, it makes measurement using the infrared camera extremely sensitive to reflections from external sources of radiation, as seen in the presented thermograms. Reflection from external sources of radiation causes a sudden local increase in temperature (detail Cin Figs. 10 and 11). It is also visible in Figs. 12-14, in which the variations of temperature determined along line Li1-Li3 (see Fig. 11) are presented.

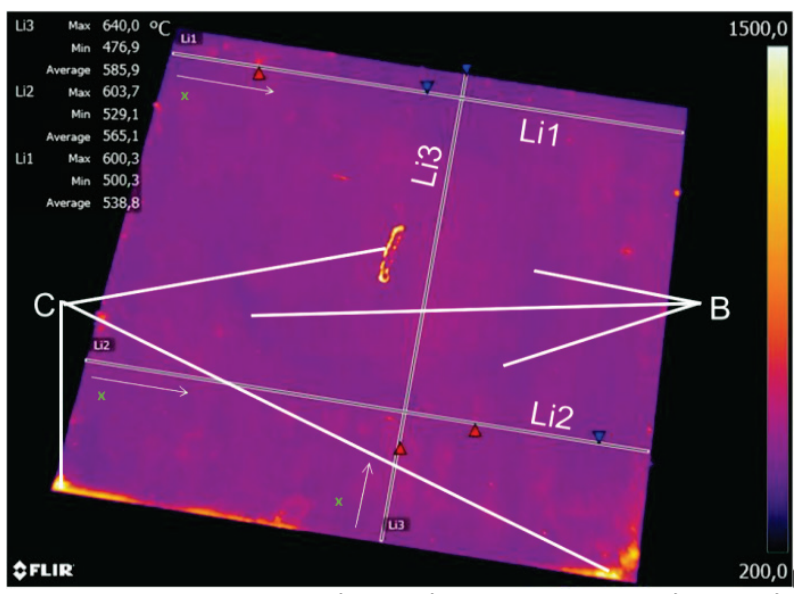

Figure11 Thermogram II: identification of average temperature after time of 414.5 seconds and measuring lines (Li1-Li3) of temperature variation

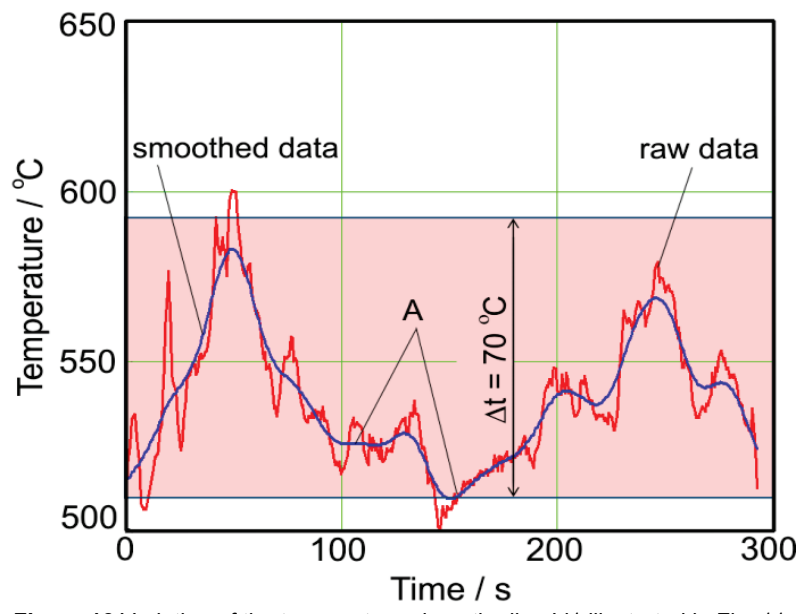

Figure 12 Variation of the temperature along the line Li1 illustrated in Fig. 11

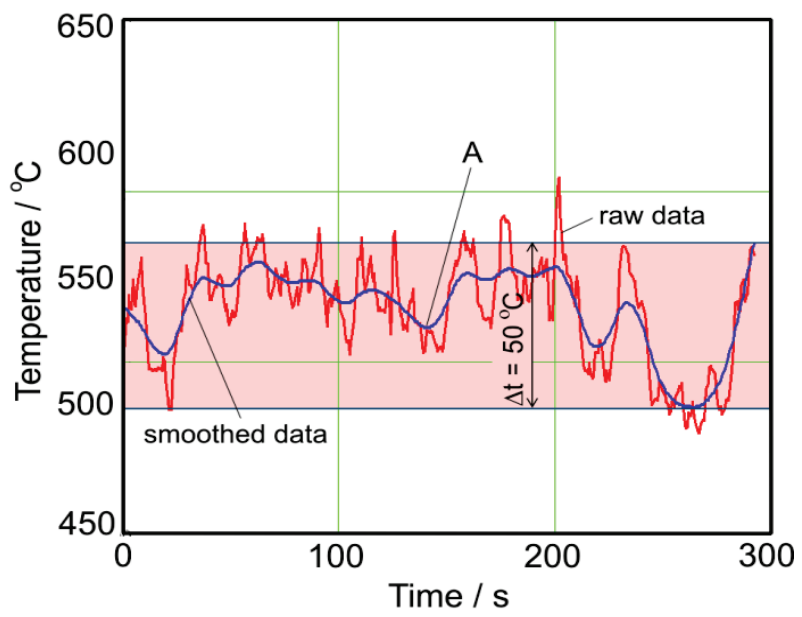

Figure 13 Variation of the temperature along the line Li2 illustrated in Fig. 11 
The area that was in contact with the robot gripper shows the lowest temperature, revealing that the heat losses to the environment and gripper are very important for the external heating method. Overheating could compensate this heat loss. It would be necessary to determine accurately the precise time of the transport phase before calculating the overheating temperature, for the time instant before the start of the deformation [7].

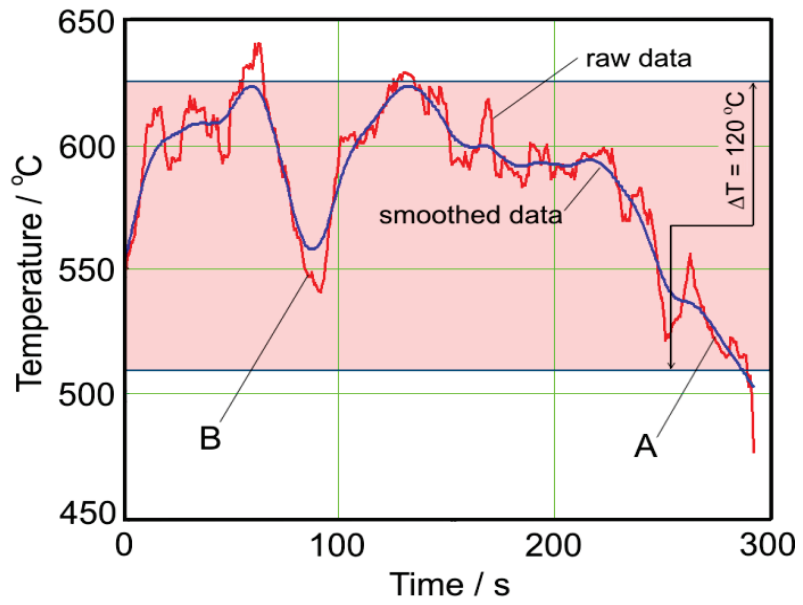

Figure 14 Variation of the temperature along the line Li3 illustrated in Fig. 11

High heat losses occur in the initial instants during the transport phase of the sheet from the heater to the stamping die, which could be balanced with an overheating. However, it is necessary to evaluate possible detrimental effects on the material that may result from the overheating [7].

\section{SUMMARY AND CONCLUSIONS}

The warm formed blank should be kept at the same temperature throughout the stamping process. In the article the external heating induction method of the blank is considered. The blank is heated in a heater until the desired temperature is reached and then transferred into the stamping tool by an industrial robot. Problems with maintaining the desired temperature in the blank can be expected since the blank has to be moved from the heater to the die. Firstly, blank heat loss exists during transferring the workpiece between the heater and the die. Secondly, the temperature of the blank decreases upon contact with the stamping tool.

In this article, it is concluded that induction heating during warm stainless steel sheet metal formation has great potential; however, several comments should be taken into account to meet production demands:

1) In order to minimise heat loss through the loading opening in the wall of the heater, a screen made of highly reflective material should be used. This would increase the heat flux density in the vicinity of the upper edge of the sheet.

2) At the initial stage of heating, the temperature difference between the maximum and the minimum temperature increases fast. This is due to the nonuniformity of the current intensity in the sheet material. The non-uniformity of the current intensity contributes to the non-uniformity of the heat flux generated in the sheet material. In the final phase of heating, the main factor contributing to the lower temperature in the vicinity of the edge of the sheet is the heat loss to the environment by radiation and convection. It should be noted that the heating process may be disturbed by atomic redistribution of material above Curie temperature at which the material becomes non-magnetic and is difficult to heat.

3) The investigations presented in this paper were conducted in real industrial conditions. The assurance of a uniform temperature distribution in such conditions is not justified economically. Although, the non-uniformity in temperature distribution is observed, the main criterion of the quality of the fabrication process is to ensure the shape and dimensional accuracy of the element. In some cases the workpiece is heated only in the selected areas.

4) Improvement of the uniformity of current intensity in the sheet and, thus, the uniformity of the heating of sheet should be achieved. This will involve a modification of the plate gripper in the resistance heater in order to reduce contact resistance between the sheet and the gripper. The degree of non-uniformity of temperature in the sheet, defined as the ratio of the difference between the maximum and minimum temperatures and the average temperature of the sheet just after the furnace switched off, is in the range of 6 to $15 \%$. The value of this ratio is high to ensure an optimum deep-drawing operation. The degree of nonuniformity of the temperature should not exceed $5 \%$.

5) The gripper of the industrial robot, which transports the sheet from the heater to the stamping tool, should be modified to reduce heat loss via conduction. Reduction of the contact area between the gripper and the sheet would be a suitable modification.

6) It was found that there are significant differences in the time taken for the sheet to heat up to the required temperature. This may be the result of significant fluctuations in the emissivity of sheet surface and high sensitivity of the pirometric temperature sensor to changes in emissivity of the surface sheet.

7) In order to increase the uniformity of temperature distribution, the heating time and transport time of the sheet from the heater to the press should be extended. During cooling down of the sheet, a decrease of the difference between maximal and minimal temperature value is observed.

\section{Acknowledgement}

The authors are gratefully acknowledged employees of the Stanisław Staszic Institute for Ferrous Metallurgy (Prof. R. Kuziak, MSc. V. Pidvysots'kyy, PhD. A. Mazur, MSc. Z. Łapczyński, PhD. W. Zalecki and MSc. R. Molenda) for conducting the thermal analyses using Gleeble simulator.

\section{REFERENCES}

[1] Trzepieciński, T., Trytek, A., \& Lemu, H. G. (2016). Study of Frictional Properties of AMS Nickel-chromium Alloys. Key Engineering Materials, 674, 244-249. https://doi.org/10.4028/www.scientific.net/KEM.674.244 
[2] Mandić, V., Erić, D., Adamović, D., Janjić, M., Jurković, Z., Babić, Ž., \& Ćosić, P. (2012). Concurrent Engineering Based on Virtual Manufacturing. Tehnički vjesnik-Technical Gazette, 19(4), 885-892.

[3] Larsson, L. (2005). Warm Sheet Metal Forming with Localized In-tool Induction Heating. Lund University, Lund.

[4] Kalpakjian, S. \& Schmid, S. R. (1997). Manufacturing Processes for Engineering Materials. $3^{\text {rd }}$ ed. AddisonWesley Publishing Company, Massachusetss.

[5] Stachowicz, F., Trzepieciński, T., \& Pieja, T. (2010). Warm Forming of Stainless Steel Sheet. Archives of Civil and Mechanical Engineering, 10(4), 85-94. https://doi.org/10.1016/S1644-9665(12)60034-X

[6] Kapustová, A. \& Görögová, I. (2016). Application of Computer Simulation for Optimization of Technological Parameters of Precision Forging. Tehnički vjesnik-Technical Gazette, 23(2), 357-361. https://doi.org/10.17559/TV-20140625102450

[7] Martins, J. M. P., Alves, J. L., Neto, D. M., Oliveira, M. C., \& Menezes, L. F. (2016). Numerical Analysis of Different Heating Systems for Warm Sheet Metal Forming. International Journal of Advanced Manufacturing Technology, 83, 897-909. https://doi.org/10.1007/s00170-015-7618-9

[8] Ghosh, M., Miroux, A., Werkhoven, R. J., Bolt, P. J., \& Kestens, L. A. I. (2014). Warm Deep-drawing and Post Drawing Analysis of Two Al-Mg-Si Alloys. Journal of Materials Processing Technology, 214(4), 756-766. https://doi.org/10.1016/j.jmatprotec.2013.10.020

[9] Schuöcker, D. \& Schröder, K. (1997). Laser Assisted Deep Drawing - a Challange for Ultra High Beam Power. Proceedings of the $30^{\text {th }}$ International CIRP Seminar on Manufacturing Systems - LANE'97 / Erlangen, 713-718.

[10] Harrison, N. R., Ilinich, A., Friedman, P., Singh, J., Verma, R. (2013). Optimization of High-Volume Warm Forming for Lightweight Sheet. SAE Technical Paper 2013-01-1170, 1170. https://doi.org/10.4271/2013-01-1170

[11] Takuda, H., Mori, K., Masuda, I., Abe, Y., \& Matsuo, M. (2002). Finite Element Simulation of Warm Deep Drawing of Aluminium Alloy Sheet when Accounting for Heat Conduction. Journal of Materials Processing Technology, 120(1-3), 412-418 https://doi.org/10.1016/S0924-0136(01)01180-3

[12] Lade, J., Banoth, B. N., Gupta, A. K., \& Singh, S. K. (2014). Metallurgical Studies of Austenitic Stainless Steel 304 under Warm Deep Drawing. Journal of Iron and Steel Research International, 21(12), 1147-1151. https://doi.org/10.1016/S1006-706X(14)60197-7

[13] Ozturk, F., Ece, R. E., Polat, N., Koksal, A., Evis, Z., \& Polat, A. (2013). Mechanical and Microstructural Evaluations of Hot Formed Titanium Sheets by Electrical Resistance Heating Process. Materials Science and Engineering A, 578, 207-214. https://doi.org/10.1016/j.msea.2013.04.079

[14] Mori, K. (2012). Smart Hot Stamping of Ultra-high Strength Steel Parts. Transactions of Nonferrous Metals Society of China, 22(2), 496-503. https://doi.org/10.1016/S1003-6326(12)61752-X

[15] Yanagimoto, J. \& Izumi, R. (2009). Continuous Electric Resistance Heating - Hot Forming System for High-alloy Metals with Poor Workability. Journal of Materials Processing Technology, 209(6), 3060-3068. https://doi.org/10.1016/j.jmatprotec.2008.07.010

[16] Mori, K., Maki, S., \& Tanaka, Y. (2005). Warm and Hot Stamping of Ultra High Tensile Strength Steel Sheets Using Resistance Heating. CIRP Annals - Manufacturing Technology, 54(1), 209-212.

https://doi.org/10.1016/S0007-8506(07)60085-7
[17] Okman, O. (2005). Free Forming of Locally Induction Heated Specimens. M.Sc. Thesis, Middle East Technical University, Ankara.

[18] Takuda, H., Morishita, T., Kinoshita, T., \& Shirakawa, N. (2005). Modelling of formula for flow stress of a magnesium alloy AZ31sheet at elevated temperatures. Journal of Materials Processing Technology, 164-165, 1258-1262. https://doi.org/10.1016/j.jmatprotec.2005.02.034

[19] Toros, S., Ozturk, F., \& Kacar, I. (2008). Review of Warm Forming of Aluminum-Magnesium Alloys. Journal of Materials Processing Technology, 207(1-3), 1-12. https://doi.org/10.1016/j.jmatprotec.2008.03.057

[20] Doege, E. \& Dröder, K. (2001). Sheet Metal Forming of Magnesium Wrought Alloys - Formability and Process Technology. Journal of Materials Processing Technology, 115(1), 14-19. https://doi.org/10.1016/S0924-0136(01)00760-9

[21] Trzepieciński, T., Nowotyńska, I., Stachowicz, F., Malinowski, T., \& Pieja, T. (2015). Thermovisual Analysis of Stainless Steel Sheet Heating. Zeszyty Naukowe Politechniki Rzeszowskiej - Mechanika, 87(4), 377-384. https://doi.org/10.7862/rm.2015.36

[22] ISO Standard 18434-1:2008. Condition Monitoring and Diagnostics of Machines - Thermography - Part 1: General procedures, International Organization for Standardization, Geneva, Switzerland.

[23] Ya, X., Peixing, Liu., Zijian, W., \& Yisheng, Z. (2014). Temperature Distribution of Boron-Manganese Sheet Metal Blank by Induction Heating in Application for Hot Stamping. Engineering, 12(5), 21-27. https://doi.org/10.15302/J-ENGI-2014026

\section{Contact information}

Robert SMUSZ, PhD. Eng

Tomasz TRZEPIECIŃSKI, DSc. PhD. Eng

Rzeszow University of Technology,

Al. Powstańców Warszawy 12, 35-959 Rzeszów, Poland

E-mail: robsmusz@prz.edu.pl

E-mail: tomtrz@prz.edu.pl

Tomasz MALINOWSKI, MSc. Eng

Tomasz PIEJA, PhD. Eng

Pratt \& Whitney Rzeszów,

ul. Hetmańska 120, 35-078 Rzeszów, Poland

E-mail: Tomasz.Malinowski@pwrze.utc.com

E-mail:Tomasz.Pieja@pwrze.utc.com 